Revista Brasileira de Cartografia

ISSN 1808-0936 | https://doi.org/10.14393/revbrascartogr

Sociedade Brasileira de Cartografia, Geodésia, Fotogrametria e Sensoriamento Remoto

\title{
A Impressão 3D no Âmbito das Representações Cartográficas
}

\section{$3 D$ Printing in Cartographic Applications}

\author{
Alan José Salomão Graça ${ }^{1}$, Juliana Moulin Fosse ${ }^{2}$, Luís Augusto Koenig Veiga ${ }^{3}$ e Mosar Faria Botelho ${ }^{4}$ \\ 1 Universidade do Estado do Rio de Janeiro, Departamento de Engenharia Cartográfica, Rio de Janeiro, Brasil. \\ alan.salomao@eng.uerj.br \\ ORCID: https://orcid.org/0000-0002-0580-6746 \\ 2 Universidade Federal Rural do Rio de Janeiro, Departamento de Engenharia, Seropédica, Brasil. jumoulin@ufrrj.br \\ ORCID: https://orcid.org/0000-0002-4221-781X \\ 3 Universidade Federal do Paraná, Departamento de Geomática, Curitiba, Brasil. kngveiga@ufpr.br \\ ORCID: https://orcid.org/0000-0003-4026-5372 \\ 4 Instituto Federal do Espírito Santo, Departamento de Geoprocessamento, Vitória, Brasil. mosar.botelho@ifes.edu.br \\ ORCID: https://orcid.org/0000-0002-6399-3500
}

Resumo: A tecnologia de impressão 3D vem revolucionando muitas práticas de projeto com a possibilidade de geração de protótipos ou peças perfeitamente funcionais nas mais diversas áreas do conhecimento, tal como a Cartografia. Diferentes tipos de produtos cartográficos confeccionados por esses métodos produtivos podem ser encontrados na literatura. Todavia, ainda pouco é explorada a questão científica de como é este processo de produção cartográfica 3D, tampouco discutida sobre esta nova forma de abordagem de produtos cartográficos tangíveis. Neste sentido, o presente artigo apresenta os conceitos de impressão 3D aplicados à Cartografia e exemplos teóricoconceituais sobre o emprego da modelagem tridimensional aliada à manufatura aditiva na geração de produtos cartográficos. São apresentadas as vantagens da impressão 3D, tais como a visualização, o tempo de produção, uso de diferentes materiais para variados produtos, que antes eram de difícil produção, além da possibilidade de geração de novas formas de representação. São destacados elementos que ainda necessitam de maiores pesquisas, tais como a simbolização, a generalização aplicada aos modelos geométricos tridimensionais, o uso de cores na impressão 3D e de textos e toponímias.

Palavras-chave: Cartografia 3D. Manufatura Aditiva (AM). Modelagem 3D. Representação 3D. Impressão 3D.

Abstract: 3D printing technology has revolutionized many design practices with the possibility of generating perfectly functional prototypes or parts in many areas of knowledge, such as Cartography. Different types of cartographic products made by these productive methods can be found in the literature. However, a very small number of researches address the scientific question of what this $3 \mathrm{D}$ cartographic production process really works in terms of cartographic communication, nor is it discussed about this new way of approaching tangible cartographic products. This article presents the concepts of 3D printing applied to Cartography and theoretical-conceptual examples on the use of threedimensional modeling combined with additive manufacturing in the generation of cartographic products. The advantages of 3D printing are presented, such as visualization, production time, use of different materials for various products, which were previously difficult to produce, in addition to the possibility of generating new forms of representation. Elements that still need further research are highlighted, such as symbolization, generalization applied to three-dimensional geometric models, the use of colors in 3D printing and texts and toponyms.

Keywords: 3D Cartography. Additive Manufacturing (AM). 3D Modeling. 3D Representation. 3D Printing.

\section{INTRODUÇÃO}

Diferentes formas de representação cartográfica tridimensional são encontradas ao longo da história, principalmente na forma de mapas de relevo ou maquetes. Até o final do século XIX, essas representações eram utilizadas com frequência para fins de ensino. Nesse contexto, a modelagem tridimensional do terreno tem sido uma ferramenta útil não somente para a Cartografia, mas para a Geografia e Geologia, desde 1752, com os primeiros globos em alto relevo da Terra (HOROWITZ; SCHULTZ, 2014). Por volta de 1890 ocorreu 
a primeira grande aplicação do chamado método de construção por camadas, Blanther desenvolveu um método didático para a construção de moldes para mapas topográficos em três dimensões (VOLPATO; CARVALHO, 2017). Basicamente o método consistia na construção de diversos discos de cera, representando as curvas de nível das cartas topográficas, obtendo-se, dessa forma, a reprodução de superfícies tridimensionais. No início do século XX, destaca-se a produção de modelos tridimensionais de relevo, principalmente para fins militares. Segundo Welker (1918) apud Pearson (2015), até 1918 mais de quarenta trabalhadores foram empregados na produção de mapas de relevo junto ao Service Geographique de l'Armee (França), e ao final da guerra, esses mapas de relevo cobriam mais de 15.000 milhas quadradas de território no fronte Western. Durante a Segunda Guerra Mundial, com os avanços da Aerofotogrametria, modelos mais detalhados de diferentes escalas foram usados para o planejamento de campanhas militares. A Fotogrametria, mais recentemente com novos algoritmos de processamento de dados e plataformas não-tripuladas, bem como outras técnicas de mensuração, como sistemas de varredura a laser, vem contribuindo para a aquisição de dados tridimensionais, como resultado, essas novas tecnologias permitem a modelagem e construção de modelos físicos da realidade em três dimensões.

No atual campo da chamada Indústria 4.0, apresentam-se inovações para uma produção mais robusta, confiável e sustentável (YURCI; DURAKBASA, 2020). Em meio a esse novo cenário, com novas tecnologias tais como IoT (Internet das Coisas), Robôs Autônomos, Computação em Nuvem, Realidade Aumentada, Big Data, a Impressão 3D tem desempenhado um papel importante com a possibilidade de geração física de produtos de forma rápida e custos acessíveis. As Ciências Cartográficas e suas áreas do conhecimento têm se beneficiado desta Indústria 4.0. A impressão 3D (também conhecida como manufatura aditiva) é um processo de fabricação avançado que pode produzir geometrias de formas complexas automaticamente a partir de um modelo 3D gerado por desenho assistido por computador (CAD) ou, no caso específico da Cartografia, de alguma técnica de levantamento tridimensional de dados geoespaciais. Bandrova (2005) diz que o uso de mapas 3D pode ser encontrado em diferentes campos da ciência, indústria e comunicação, na arquitetura e planejamento urbano, projetos de infraestrutura, bem como no ensino superior e na educação escolar. O uso e elaboração destes mapas passa necessariamente pelo processo de simbolização, sendo que ainda não há padrões definidos e vários trabalhos têm buscado estudar o assunto (BEM; PUPO, 2019; DEGREAS; KATAKURA, 2016; GUAL-ORTI et al., 2015). Da mesma maneira, para produtos cartográficos 3D impressos, não existem padrões estabelecidos, uma vez que a discussão passa necessariamente pelos diferentes produtos e suas finalidades.

Atualmente o termo impressão 3D vem coloquialmente sendo aplicado a todos os tipos de fabricação aditiva incluindo fusão e estereolitografia, e os processos de extrusão, laminação, sinterização. A impressão 3D está rapidamente se tornando cada vez mais viável como método de produção, avançando desde suas origens como uma tecnologia da Indústria 4.0, presente hoje na fabricação corporativa e domiciliar.

À medida que essa disseminação se torna cada vez mais acessível, a confecção de produtos tridimensionais, incluindo produtos cartográficos, começa a se popularizar. Nesse contexto, aplicações de conceitos cartográficos fundamentais como escala e generalização são importantes para os usuários compreenderem o mapa e as demais representações de objetos tridimensionais. Mesmo com mudanças significativas nas formas de produzir mapas, alguns princípios aplicados ao projeto cartográfico discutidos por Robinson et al. (1995) possuem relevância no planejamento do mapa impresso em 3D. Os elementos de controle do projeto cartográfico servem como orientação inicial para que o profissional da Cartografia possa considerar os fatores que irão interferir de forma direta no resultado do seu produto cartográfico. Esses elementos de controle correspondem aos objetivos do mapeamento, os limites técnicos e tecnológicos, a escala, a realidade a ser mapeada e o público-alvo.

Hoje o que se percebe é uma concentração de trabalhos que versam sobre mapas táteis quando se aborda a questão de impressão $3 \mathrm{D}$ aplicada à representações cartográficas, devido à própria característica volumétrica dessas representações tangíveis, onde a produção através destas técnicas tem mostrado profunda mudança na forma de elaboração dos mesmos. Mas quais seriam as outras possibilidades de representação? E mesmo para mapas táteis, quais os novos padrões podem ser incorporados ao layout desses produtos?

No presente trabalho busca-se apresentar os conceitos relacionados à impressão $3 \mathrm{D}$ e exemplos 
teórico-conceituais sobre o emprego da modelagem tridimensional aliada à prototipagem rápida na geração de produtos cartográficos, apresentando diferentes soluções e aplicações para a impressão 3D na Cartografia, e buscando apontar direções que ainda devem ser exploradas e pesquisadas.

\section{REVISÃO TEÓRICA}

\subsection{Manufatura aditiva e impressão 3D}

O termo Additive Manufacturing (AD), pode ser ainda pouco conhecido entre os profissionais da Cartografia no geral ou sua aplicação na produção de mapas físicos. O AD é definido como o processo de junção de materiais para criar peças a partir de dados provenientes de um modelo 3D, geralmente camadas sobre camadas, em oposição às metodologias de fabricação subtrativa e de fabricação formativa ou processo de conformação (ISO/ASTM 52900:2015). As tecnologias de AD surgiram na década de 80 (SANTOS, 2017; VOLPATO; CARVALHO, 2017) e envolvem diferentes tipos de materiais usados na produção do objeto 3D e de tecnologias. Nos anos 90, os avanços ligados à informática voltada para o uso de computadores pessoais permitiram que designers começassem a explorar diversas possibilidades de aplicação da $\mathrm{AD}$, possibilitando maior liberdade geométrica para a construção de estruturas físicas tanto simples quanto complexas (SANTOS, 2017).

A impressão 3D baseia-se na criação de objetos por camadas, conectando sucessivas seções paralelas de material. As camadas podem ser formadas por um pó fino, resinas ou pela fusão de polímeros, que são depositados seletivamente por "impressão", realizada de acordo com o sistema empregado, tomando como base o arquivo 3D do objeto a ser impresso. Esse processo automatizado de fabricação é aplicado a diversos campos industriais, devido às vantagens significativas da criação de protótipos funcionais com menos intervenção humana, menores custos em relação a outros processos de fabricação industrial (usinagem, fundição, injeção plástica etc.), em menor tempo de construção e com desperdício mínimo de material.

Segundo Borille (2016), formas mais baratas e acessíveis de AD tornaram-se disponíveis, como as atuais impressoras $3 \mathrm{D}$, e que em relação aos equipamentos para a $\mathrm{AD}$, diferenciam-se dois grupos principais: as impressoras 3D (3D-Printers) e as máquinas industriais (non-3D-Printers). Diferentes processos de $\mathrm{AD}$ normalmente são diferenciados pelo material que a peça é executada (polímero, metal, resina etc.), sua característica física (pó, líquido ou sólido) e o mecanismo utilizado para a consolidação deste material e produção do objeto (como fusão, solidificação, polimerização e laminação).

A ISO/ASTM 52900:2015 define que:

Impressão 3D é a fabricação de objetos por meio da deposição de um material usando uma cabeça de impressão, bocal ou outra tecnologia de impressão e o termo é frequentemente usado em um contexto não técnico como sinônimo de $\mathrm{AD}$ e atualmente este termo tem sido associado em particular a máquinas que são de baixo custo e/ou capacidade geral (Tradução dos autores).

Todas as peças no processo de $\mathrm{AD}$ devem começar a partir de um modelo virtual desenvolvido em software que descreve completamente a sua geometria (GIBSON et al., 2010), isto é, inicia-se com a modelagem computacional do objeto. Este deve ser entendido como um sólido e não apenas como um arquivo vetorial tradicional. Isso pode envolver o uso de praticamente qualquer modelagem sólida em um software profissional de CAD, desde que a saída seja uma representação sólida ou de superfície 3D. Por conseguinte, este modelo deve ser exportado para algum dos tipos de arquivos utilizados pelas impressoras, por exemplo, o STL.

O arquivo STL é derivado da palavra inglesa STereoLithography (estereolitografia) e foi o primeiro processo comercial de AD, produzido em 1988 pelo Albert Consulting Group, sob demanda da empresa norteamericana 3D Systems Inc. (FOGGIATTO; SILVA, 2017; GIBSON et al., 2010). Este formato de arquivo descreve a superfície geométrica de um objeto como uma rede de triângulos (tessellation of triangles) e é usado para informar a geometria 3D para máquinas de forma a construir o objeto físico (ISO/ASTM 52900:2015). Ainda, segundo a norma, é conhecido também por Standard Triangulation Language ou Standard Tessellation 
Language, mas não há uma nomenclatura padrão. Segundo Foggiatto e Silva (2017), o STL é um formato simples, porém robusto para representar os produtos derivados da modelagem tridimensional. A Figura 1, é representada por um modelo 3D em STL do Monte Fuji. Toda a geometria do modelo foi generalizada através de triângulos (Figura 1), no qual podem ser observadas as faces triangulares em uma visão geral (a) e numa visão mais próxima e detalhada (b). Quanto maior o detalhamento desejado, maior será o número de triângulos e, consequentemente, o tamanho do arquivo STL.

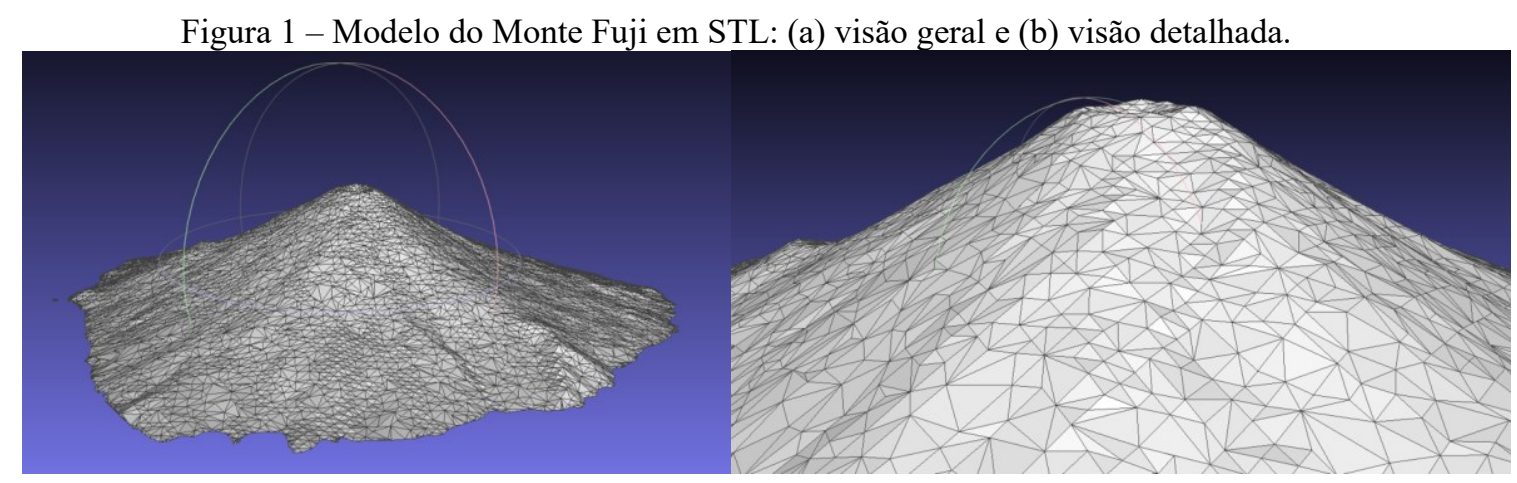

(a)

(b)

Fonte: Os autores (2021).

Posteriormente, este arquivo é submetido ao processo denominado de fatiamento, onde um software faz a leitura do objeto (arquivo STL) e define as diversas camadas que serão impressas. Esta é uma etapa importante, pois são definidas as alturas de cada camada, a porcentagem e o tipo de preenchimento do interior da peça, a temperatura que será utilizada na extrusora e a velocidade do fluxo, entre outras variáveis, que terão impacto direto nas características do produto impresso. A Figura 2 ilustra o mesmo arquivo do Monte Fuji em STL, após o processo de fatiamento (a) e com o fatiamento visto a partir de uma camada intermediária (b).

Figura 2 - Modelo do Monte Fuji em STL: (a) após o processo de fatiamento e (b) com o fatiamento visto a partir de uma camada intermediária.

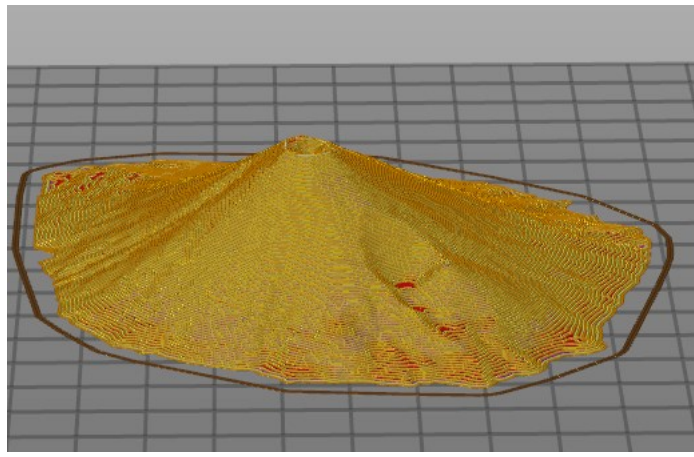

(a)

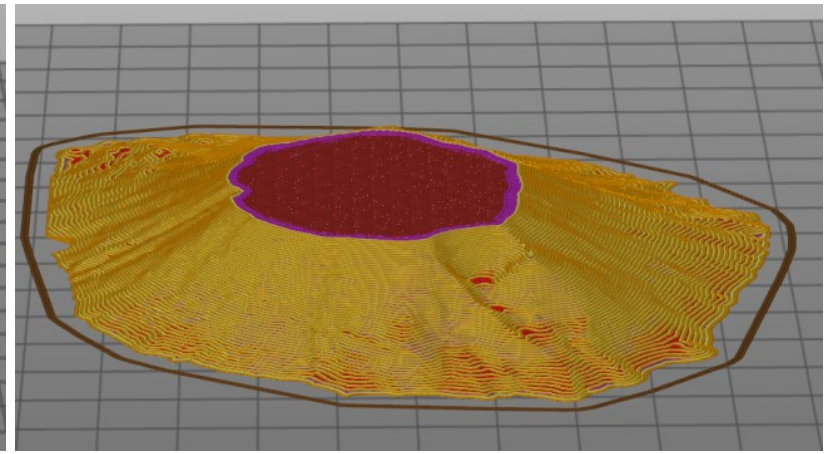

(b)

Fonte: Os autores (2021).

Porém o modelo ainda não está pronto para a impressão, é necessário gerar um conjunto de comandos para que a impressora 3D possa movimentar sua cabeça de impressão e depositar o material no lugar correto. Isto é feito através da geração do chamado código $\mathrm{G}$ ( $G$-code). Este código foi criado para enviar comandos para máquinas executarem determinadas tarefas, é uma linguagem específica para este fim. Este arquivo no formato G-code é enviado às impressoras e as mesmas executam a impressão 3D. A próxima etapa é a construção física do objeto, camada por camada. A Figura 3, ilustra o modelo do Monte Fuji sendo impresso (a) e o resultado (b) após a impressão finalizada. Para este exemplo de dimensões aproximadas de $10 \mathrm{~cm}$ de diâmetro de base e $2 \mathrm{~cm}$ de altura, a distância entre as camadas foi de $0,02 \mathrm{~mm}$ (resolução da camada), resultando em 104 camadas, com o gasto de $8 \mathrm{~m}$ de filamento e $2 \mathrm{~h} 30$ min de tempo de impressão. Em alguns casos existe a necessidade de dar algum tipo de acabamento no produto, como remover sustentações ou suportes (caso existam), infiltrar resina para aumentar a resistência do material, melhorar o acabamento com 
jateamento de pigmentação colorida (ColorJet Printing, por exemplo) e lixar arestas ou pequenos defeitos oriundos do processo de impressão. Esse acabamento é definido na literatura, por autores como Gibson et al. (2010) e Volpato e Silva (2017) como etapa de pós-processamento.

Figura 3 - Impressão do modelo 3D: (a) sendo impresso e (b) resultado da impressão.

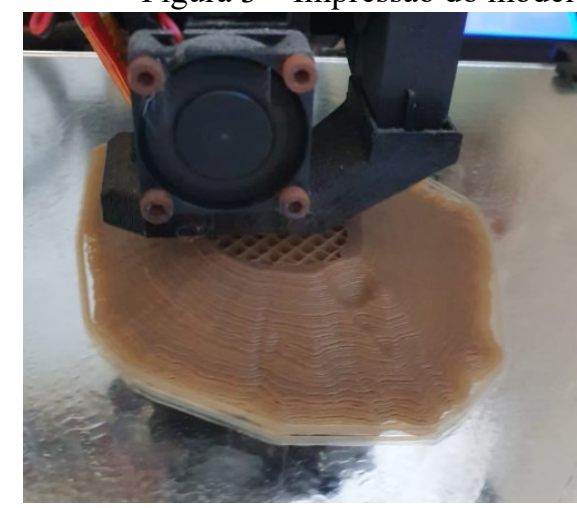

(a)

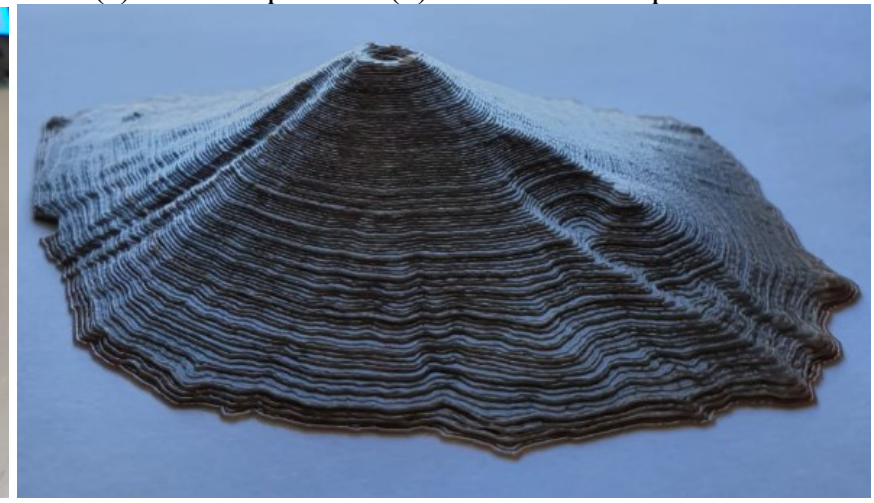

(b)

Fonte: Os autores (2021).

\subsubsection{FABRICAÇÃO COM FILAMENTO FUNDIDO (FUSED DEPOSITION MODELING - FDM)}

Impressoras que trabalham com este princípio baseiam-se na fusão e deposição do material a ser empregado na impressão. Segundo Pecho et al. (2019), atualmente o FDM é o método mais popular e difundido para imprimir objetos 3D (tais como protótipos funcionais, modelos conceituais e designs auxiliares de fabricação em linhas de produção), principalmente devido à simplicidade desse processo de impressão. A extrusão empurra o material, normalmente um filamento termoplástico, através de um bico extrusor para uma plataforma que se move no plano x, y, z. O FDM pode usar diferentes tipos de filamentos, os três mais conhecidos são os filamentos PLA, PETG ou ABS, mas também inclui misturas de NYLON, PC, TPU ou PLA (misturado com madeira, cerâmica etc.). Os filamentos PLA estão disponíveis em várias cores e o diâmetro do filamento está disponível em dois tamanhos padronizados: 1,75 ou $2,85 \mathrm{~mm}$.

De acordo com Greiser (2019):

Para impressoras FDM, a resolução da impressora é um fator relacionado ao tamanho do bico e da precisão dos movimentos da extrusora (eixo X / Y). A precisão e suavidade dos modelos impressos também são influenciadas por outros fatores: como a força de ligação entre as camadas é menor do que na impressão SLA e como o peso das camadas superiores pode comprimir as camadas abaixo, uma série de problemas de impressão podem ocorrer (por exemplo empenamento, desalinhamento de camadas, deslocamento de camadas, encolhimento das partes inferiores (Tradução dos autores).

Em resumo, esse processo consiste em estratificar o material derretido, camada por camada, na plataforma de impressão, e usando esta tecnologia, é possível obter detalhes realmente finos no acabamento dos objetos, com uma excepcional relação resistência/peso, dado o fato que os produtos gerados são leves e sendo bem construídos apresentam uma durabilidade considerável. Além disso, outro estímulo a popularização e barateamento das tecnologias de impressão FDM são iniciativas de compartilhamento de tecnologias de hardware e software Open Source para a produção de impressoras 3D, como por exemplo o pioneiro projeto RepRap (https://reprap.org/wiki/RepRap) discutido no estudo de Fernandes et al. (2016).

\subsubsection{ESTEREOLITOGRAFIA (SLA)}

A impressão estereolitográfica (SLA) funciona curando uma determinada resina com luz, usando um processo chamado fotopolimerização e construindo objetos camada por camada. Existem dois tipos principais de tecnologia SLA: baseada em laser (SLA) e baseada em projeção (DLP - Projeção Digital de Luz). A principal diferença entre eles é a fonte de luz, onde no segundo caso, em vez de laser, é usada uma tela do 
projetor abaixo do tanque de resina para exibir uma imagem de toda a camada em toda a plataforma. A incidência de luz inicia a reação química na resina fotopolimérica líquida, e assim, dá início ao seu processo de solidificação em uma cuba ou reservatório. Conforme o polímero cura e endurece, a impressão é deslocada, e outra camada de polímero é curada diretamente na camada anterior.

De acordo com Greiser (2019):

As impressoras SLA produzem consistentemente objetos de alta resolução e são mais precisas do que as impressoras FDM. O motivo: a resolução é determinada principalmente pelo tamanho do ponto óptico do laser ou do projetor - e isso é realmente pequeno. Além disso, durante a impressão, menos força é aplicada ao modelo. Dessa forma, o acabamento da superfície é muito mais liso. As impressões SLA mostram detalhes que uma impressora FDM nunca poderia produzir (Tradução dos autores).

A Figura 4 (a) apresenta um exemplo de impressora que utiliza o princípio do FDM, e a Figura 4 (b) apresenta um exemplo de impressora que utiliza o princípio do SLA.

Figura 4 - Tipos de impressora: (a) FDM e (b) SLA.

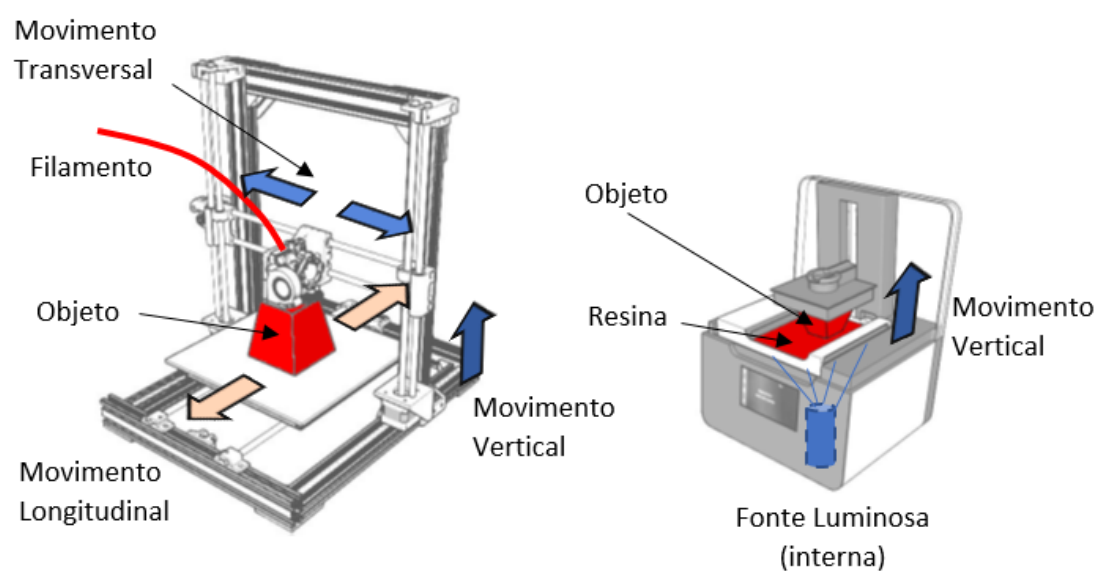

(a)

(b)

Fonte: Os autores (2021).

A principal vantagem do SLA é que ele pode produzir peças altamente precisas e detalhadas, onde modelos 3D mais robustos (com alta resolução e detalhes) poderão ser representados de forma mais fidedigna (AHRENS, 2017). No entanto, o mesmo requer um tempo adicional de cura da resina e lavagem da peça pósimpressão com álcool isopropílico para a retirada do excedente da resina não curada.

\subsection{Métodos e tecnologias para aquisição dos dados tridimensionais}

O processo de aquisição de dados tridimensionais envolve múltiplas tecnologias, desde sistemas integrados de captura de realidade como scanners 3D até os tradicionais equipamentos de levantamentos topográficos. Tradicionalmente os dados tridimensionais eram obtidos por mapas com representação de curvas de nível, inicialmente em meio analógico e mais ao final do século XX através de arquivos digitais. Outras feições existentes, como edificações, eram medidas in loco ou por técnicas de Fotogrametria. A produção de mapas e de outras representações tridimensionais passam necessariamente pelo processo de coleta ou aquisição dos dados tridimensionais. Este processo tem influência direta no processo de modelagem e impressão 3D dos elementos a serem representados.

No final da década de 80 , no século XX, o surgimento de equipamentos de mensuração empregando laser como onda de medida e, consequentemente, sem a necessidade de acessórios para a reflexão dos sinais emitidos, tornou o levantamento tridimensional mais prático e rápido, bem como permitiu o levantamento 3D diretamente em campo. Na sequência vieram os equipamentos de varredura a laser, que empregam o mesmo 
princípio de funcionamento, porém permitiram a coleta de milhares a milhões de pontos por segundo (PETRIE; TOTH, 2018). Enquanto no primeiro caso existe a necessidade de discretizar o elemento levantado pelos seus pontos descritores, no segundo, a estrutura é completamente varrida (levantada) havendo uma grande redundância de pontos, principalmente em superfícies planas. O produto obtido por esta técnica é conhecido por nuvem de pontos, ou seja, um conjunto de pontos com coordenadas tridimensionais conhecidas.

$\mathrm{Na}$ área da Fotogrametria, as técnicas tradicionais permitem a determinação de coordenadas tridimensionais de pontos a partir de processos estereoscópicos, que também demandam a identificação e a mensuração de pontos de interesse. O destaque para a coleta de dados tridimensionais por técnicas fotogramétricas veio a introdução da visão computacional na Fotogrametria a curta distância, em especial com utilização de câmeras não-métricas e a aplicação da técnica Structure from Motion (SfM). De acordo com Zhou et al. (2016) esta é uma técnica que busca simultaneamente determinar o movimento da câmera e a estrutura tridimensional (3D) de uma cena a partir de uma série de imagens bidimensionais (2D). Um dos principais produtos da aplicação desta técnica é a geração de uma nuvem de pontos 3D que representa a feição levantada.

Como visto, o processo de impressão 3D passa pela geração do arquivo, antes da impressão 3D, onde toda a geometria da feição é determinada por uma triangulação. É neste ponto que o método de coleta começa a ter uma grande influência no processo de modelagem. Uma grande quantidade de pontos com distribuição homogênea em toda a feição levantada tende a conduzir a uma modelagem mais precisa do objeto. Porém, por outro lado, isto afeta de forma proporcional o tempo de produção do modelo e a geração do arquivo STL, bem como o processo de impressão 3D em si. Além disso, em função da redução da escala do objeto no momento da impressão 3D, fará com que exista uma generalização nas formas do produto. Imagine-se uma parede plana levantada pelo método de varredura a laser, onde existem variações de poucos milímetros nas coordenadas que representam a face da mesma. Na impressão 3D não será detectável esta variação.

Assim, uma etapa necessária antes da modelagem das feições é a generalização através de processos de seleção de pontos a serem usados no processo de modelagem. Outra forma é a reconstrução de geometrias a partir das nuvens de pontos, processo este que pode ser feito de forma automática ou manual. Uma nuvem de pontos que representa um cilindro será generalizada para a representação geométrica do mesmo, diminuindo significativamente o número de pontos necessários para representar e armazenar esta feição.

\subsection{Elementos Cartográficos e o Processo de Impressão 3D}

Na Cartografia o objetivo é essencial e determinante para cumprir o propósito da comunicação cartográfica para o qual o mapa foi proposto. Ele responde diretamente a pergunta: "O que se espera desse mapa?”. Todos os aspectos de simbolização 3D, tanto das feições individualizadas bem como a aparência geral do mapa devem estar direcionados para que se atinja o objetivo proposto. Para cumprir com seu objetivo, o mapa impresso por $\mathrm{AD}$ deve prezar pela simplicidade, com justaposição entre as feições de maneira que possibilite uma fácil leitura do todo. O limite técnico afeta o produto impresso de diferentes formas, por exemplo, uso de cores de filamentos, orientação e tamanho de textos. Num mapa 3D tátil, por exemplo, o tamanho dos textos braile é pré-definido pela norma NBR 9050:2015 para que o usuário possa decodificar a informação com as pontas dos dedos. Pelo fato do tamanho da cela braile ser bastante reduzida, isso pode se tornar uma grande dificuldade em sua produção, em função da resolução de impressão. Em contraponto, temse o tamanho máximo de impressão nas dimensões xy, que se limita ao espaço da mesa de impressão. Logo, para áreas muito extensas o projeto deve prever a necessidade de subdividir o modelo 3D para depois realizar a junção das partes impressas em separado. Isso também vale para a dimensão $z$, limitada pela altura da área de impressão.

Alguns processos que utilizam FDM podem criar produtos em cores. Quando existe a necessidade de impressão de modelos coloridos é possível dividir as impressoras 3D em dois grupos: impressão colorida direta e indireta. No processo de impressão direta é possível executar a impressão usando diferentes cores, que correspondem às diferentes cores dos filamentos utilizados. Para impressoras de filamento que possuem uma única extrusora (ou bico extrusor) é possível definir no arquivo de impressão ( $G$-code) pontos de parada para a troca manual do filamento e assim, alterar as cores a serem utilizadas. Entretanto, já existem impressoras com duas ou mais extrusores, permitindo assim, de forma mais automatizada a troca do filamento a ser 
utilizado. A geração de peças em cores já na impressão pode reduzir, ou mesmo eliminar a necessidade de etapas posteriores de pintura durante a produção. Para a impressão colorida indireta, existe a possibilidade de uso de pigmentos que são aplicados ao material de impressão no momento da impressão 3D. Estes materiais podem ser filamentos, resinas e diversos tipos de pó, e normalmente usam sistema CMYK. A cor pode ser usada como uma ferramenta de comunicação para destacar características que vão desde tumores em modelos médicos a diferenças de matizes para mapear dados analíticos em mapas estatísticos, tornando dessa maneira, as informações mais fáceis de serem compreendidas e discutidas (THOMPSON et al., 2016).

Quanto à escala da representação, deve-se buscar manter relações de proporcionalidade para que o tema mapeado possa ser bem compreendido. Quando se trata de uma única impressão de objeto ou produto cartográfico, a escala para ser definida deve estar coerente com a limitação tecnológica que é o tamanho da mesa de impressão. Plotagens maiores que o tamanho da mesa deverão ser pensadas de forma a gerar o produto final através da combinação de partes impressas, porém este processo pode demandar um trabalho de acabamento maior do produto, para evitar que as junções fiquem destacadas. Em relação ao exagero vertical empregado no eixo z, não há uma padronização ou uma sugestão bibliográfica sobre qual proporção deve ser adotada.

A generalização é um elemento relacionado diretamente com o processo de redução de escala. Poucos trabalhos sobre o assunto foram produzidos especificamente para o caso da impressão 3D, entre eles Štampach e Mulíčková (2016) e Touya et al. (2018). Para solucionar a dubiedade de interpretações em trechos de rodovias. Štampach e Mulíčková (2016) apresentam o emprego de operadores de eliminação para excluir rotatórias de trajetos e simplificação sobre os viadutos. Para os loteamentos os autores utilizaram o operador de amálgama (combinação) deixando somente a feição das quadras e para os diferentes tipos de zoneamentos urbanos optaram pelo uso do operador de reclassificação. Cabe frisar que ambos os casos Štampach e Mulíčková (2016) voltaram-se especificamente a mapas tridimensionais com símbolos geométricos, destinados a deficientes visuais. Trabalhos direcionados para a generalização de modelos fotorealísticos não foram encontrados na literatura discutida nesse artigo.

\section{PROCESSO DE PRODUÇÃO E APLICAÇÕES}

A distinção realizada entre modelo e mapas neste artigo deve-se ao fato da geração de produtos gerados sem a pretensão de utilizar-se dos preceitos cartográficos aplicados à produção de mapas, sendo empregados mais para o uso em aplicações didáticas de forma a ilustrar conceitos relacionados à Geografia e à Cartografia. Cabe salientar que em paradigmas epistemológicas da Cartografia, como por exemplo, a Comunicação Cartográfica (BOARD, 1975; SALISHCHEV, 1985), Cartografia Digital e Interativa (ASCHE; HERRMANN, 1994; KRAAK; ORMELING, 2010), e a Coremática (BRUNET, 1987; MARTINELLI; SALOMÃO GRAÇA, 2015) às relações entre modelo e mapa se dão de formas distintas do que está sendo discutido aqui. Os autores aqui compreendem a importância das concepções de mapas como modelos gráfico-simbólicos da realidade (BERLYANT, 1994), bem como modelos de representação de dados geoespaciais (KRAAK; ORMELING, 2010), porém no contexto da AD, para tornar a leitura mais fluída e compatibilizar as discussões com literaturas produzidas fora do contexto das ciências cartográficas, optou-se por essa separação entre os termos 'modelo' e 'mapa'.

Dois modelos físicos para fins didáticos são apresentados na Figura 5. A Figura 5 (a) ilustra um globo impresso em PLA vermelho, com diâmetro de $8 \mathrm{~cm}$. A Figura 5 (b) ilustra um Modelo Digital de Terreno (MDT) simulando curvas de nível, impresso com filamento PLA de várias cores para ilustrar as diferenças de altura do terreno. Exemplos como esses podem facilitar o processo de ensino-aprendizagem nas aulas de Geomorfologia e Geografia Física. O grau de complexidade destes modelos depende do objeto ou do conjunto de feições que se deseja representar. Uma vantagem é que atualmente existem inúmeros projetos relacionados ao ensino da Cartografia, disponíveis em sites especializados em arquivos para impressão 3D, como por exemplo, o portal Thingiverse.com, de onde os modelos das Figuras 5 foram obtidos e impressos pelos autores. 
Figura 5 - Impressões em PLA: (a) globo terrestre e (b) MDT.

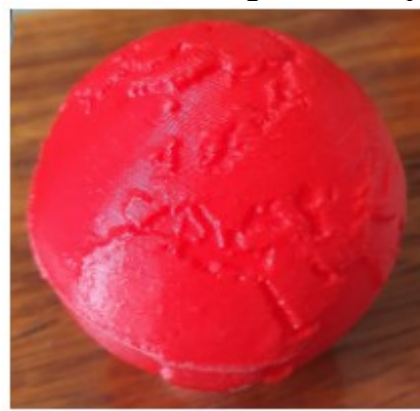

(a)

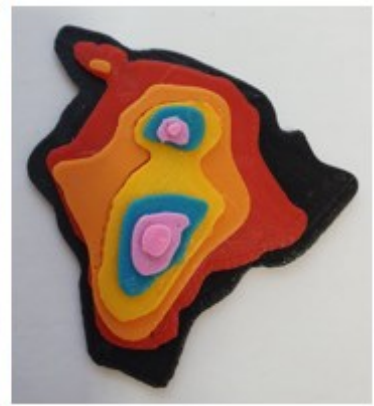

Fonte: Os autores (2021).

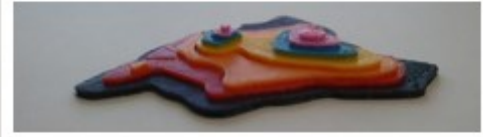

(b)

Em virtude dos avanços recentes na tecnologia de $\mathrm{AD}$, impressoras $3 \mathrm{D}$ de baixo custo são capazes de utilizar arquivos de impressão gerados a partir de dados de cartas topográficas, de radar de abertura sintética (SRTM, por exemplo), de altimetrias obtidas por diferentes tecnologias de aquisição (Laser Scanner, Fotogrametria Digital, Sonares) e modelos digitais de representação do relevo e/ou superfícies e transformálos em modelos físicos precisos e manuseáveis em questão de poucas horas. Modelos resultantes de impressões de baixo custo não apenas fornecem materiais de estudo para elementos planetários e pequenos corpos celestes, como também permitem a geração de bibliotecas de objetos físicos acessíveis aos portadores de deficiências visuais (HOROWITZ; SCHULTZ, 2014).

Para a modelagem 3D de produtos cartográficos pode-se citar alguns softwares já conhecidos da comunidade cartográfica, como o QGIS, software livre com código-fonte aberto. Entretanto é necessário o uso adicional de algum complemento que permita a geração do modelo 3D. O complemento QGIS2threejs permite gerar um modelo 3D a partir de arquivos no formato shapefile, seja um modelo para visualização no browser de internet ou em formato STL para ser impresso. Há duas possibilidades de estabelecer o valor da variável z: atribuindo um valor único de extrusão para todos os polígonos do arquivo shapefile ou com a criação de uma coluna de valores na tabela de atributos, onde tais valores corresponderão aos valores do atributo z referente a cada polígono da camada a ser feita a extrusão. De forma semelhante, um levantamento topográfico planialtimétrico representado em um arquivo de formato DWG ou DXF pode ser impresso. Nesse caso é necessário converter o arquivo original para o formato vetorial em SHP e estabelecer o valor da variável z para a extrusão. A Figura 6 ilustra um modelo 3D do município do Rio de Janeiro gerado com o complemento QGIS2threejs. Neste modelo, o município do Rio de Janeiro está dividido em bairros, onde a variável visual luminosidade (value) e altura corresponde a oito diferentes classes de densidade demográfica. Quanto mais alto, maior é a densidade demográfica do bairro. Este é um exemplo de mapa temático 3D. A Figura 6 (a) e (b) ilustra o modelo 3D gerado pelo complemento QGIS2threejs no módulo visualização, em perspectiva frontal e inclinada, respectivamente. A Figura 6 (c) apresenta o modelo 3D impresso em filamento PLA nas dimensões aproximadas de $15 \mathrm{~cm}$ x $8 \mathrm{~cm} \times 2 \mathrm{~cm}$.

Figura 6 - Modelo 3D do município do Rio de Janeiro: (a) vista frontal, (b) vista inclinada e (c) modelo impresso.

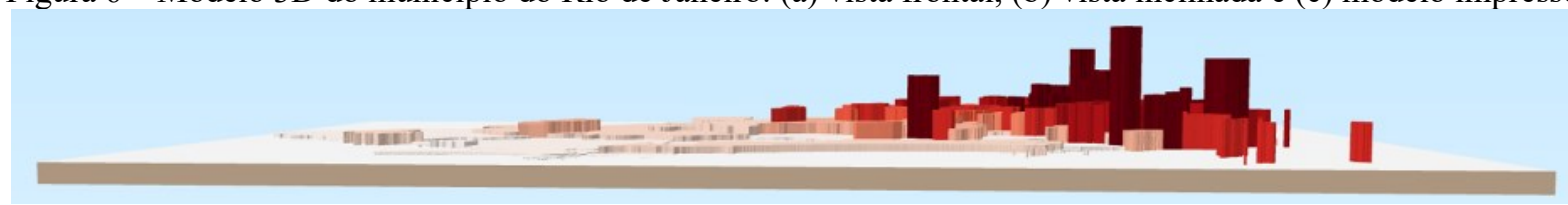

(a)

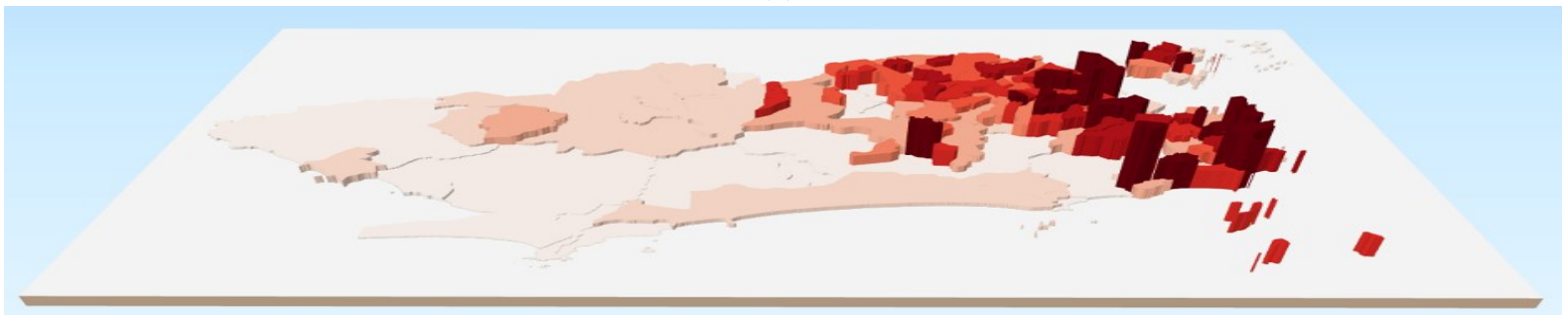

(b) 


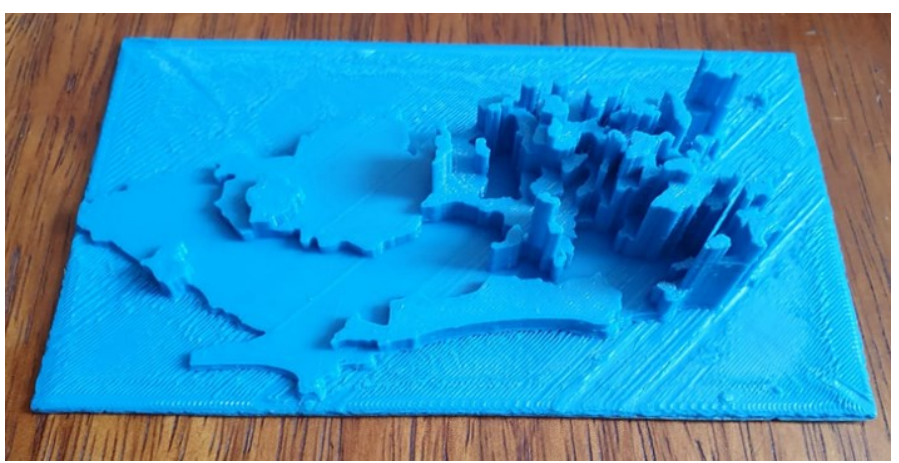

(c)

Fonte: Os autores (2021).

Outra maneira de realizar a modelagem 3D é através da utilização de um software fotogramétrico que permite a geração de uma nuvem de pontos. Alguns softwares fotogramétricos permitem transformar essa nuvem de pontos em modelos compostos por faces, quase sempre triangulares, e assim gerar um modelo apto para ser impresso, como, por exemplo, o Agisoft Metashape, Inpho, o Pix4D e soluções de software livre como GRAPHOS, MicMac e Visual SFM. A Figura 7 (a) ilustra um terreno onde foi realizado um levantamento fotogramétrico com veículo aéreo não-tripulado (VANT), os dados foram processados no software fotogramétrico Pix 4D, e exportados posteriormente para a extensão STL. Foi criada uma base de apoio para o modelo no aplicativo Windows 3D Builder e o produto foi impresso, como ilustra a Figura 7 (b). O modelo 3D possui uma escala aproximada de 1:5000 em xy e 1:600 em z em comparação com o terreno original.

Figura 7 - Modelo 3D gerado a partir de dados fotogramétricos feito com VANT: (a) modelo do terreno e (b) modelo

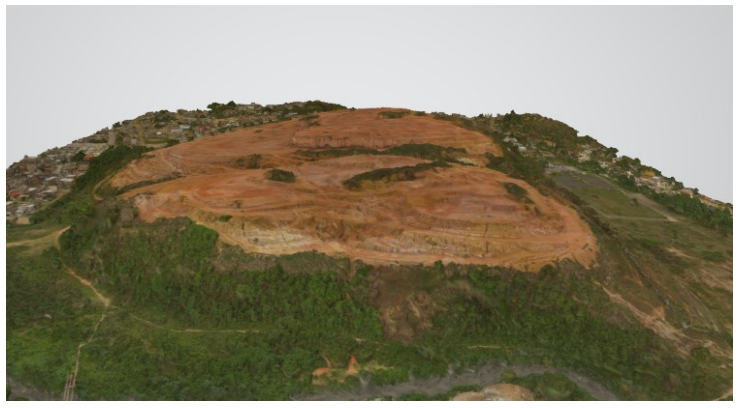

(a) impresso.

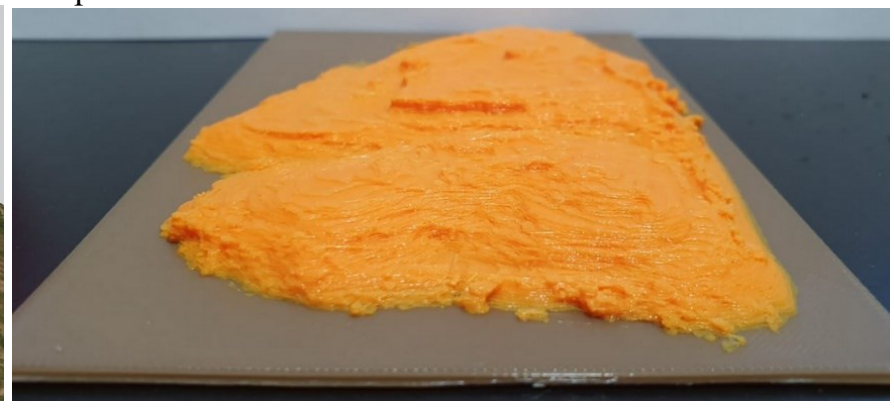

(b)

Fonte: Os autores (2021).

Alguns aplicativos, tais como o Terrain2STL (JThatch.comjthatch.com) e o TouchTerrain (HASIUK et al., 2017), gratuitos e disponíveis online, podem gerar de forma automática modelos 3D em extensão STL a partir de dados SRTM (Shuttle Radar Topography Mission), de 2000, com resolução de 90 m. Para a geração do modelo é necessário acessar o site e estabelecer alguns parâmetros, tais como, localização da área a ser gerada o modelo, tamanho da área, exagero vertical etc. A Figura 8 ilustra um exemplo de representação cartográfica 3D impressa da Ilha Grande, Angra dos Reis - RJ, gerado no aplicativo Terrain 2STL, com exagero vertical de 2x e impresso em PLA em duas cores. Para completar o modelo, foi feita uma base de apoio no aplicativo Windows $3 D$ Builder. O aplicativo TouchTerrain funciona de forma semelhante ao aplicativo Terrain2STL. 
Figura 8 - Modelo 3D impresso gerado a partir de dados SRTM usando a aplicativo Terrain2STL.

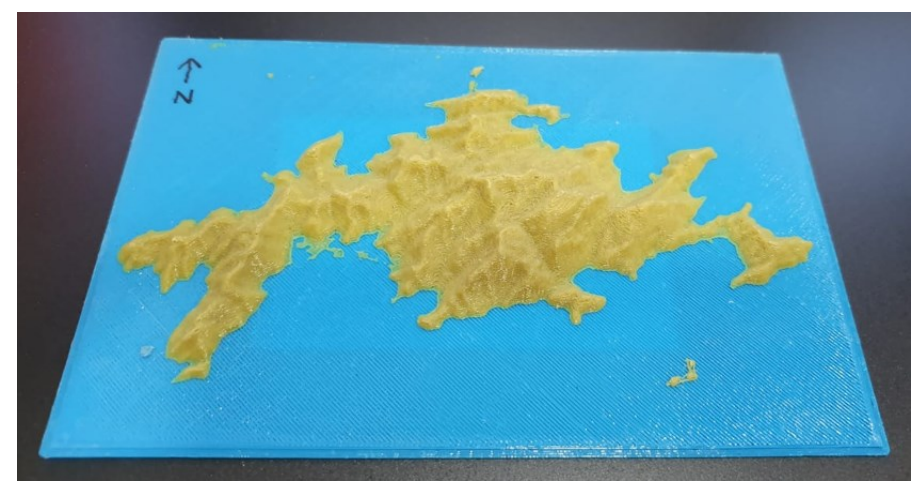

Fonte: Os autores (2021).

Em oposição aos softwares livres de modelagem 3D, estão disponíveis vários softwares proprietários, dentre eles podemos citar o SolidWorks, o SketchUp e o Fusion360, FreeCAD, bastante conhecidos entre os modeladores. Esses softwares possuem aplicações amplas nas áreas de planejamento urbano, construção e patrimônio cultural, e sua conversão para projetos impressos requer modelos físicos que sejam ao mesmo tempo geometricamente precisos, visualmente agradáveis e de fácil compreensão, especialmente se os objetos impressos forem usados para fins de apresentação e exposição (VIRTANEN et al., 2014). O exemplo apresentado a seguir foi modelado no SolidWorks (https://www.solidworks.com/pt-br), no qual foram modeladas e impressas mais de sessenta peças, para formar uma maquete tátil. Esta maquete representa o Museu da Imigração de São Paulo e foi projetada para ser tateada por pessoas portadoras de deficiência. A maquete tem aproximadamente $1 \mathrm{~m}$ x $1 \mathrm{~m}$ de área impressa. A legenda, feita em texto braile, foi feita a parte, por outra técnica de produção. A Figura 9 ilustra a maquete tátil do Museu do Imigrante de São Paulo, cujas peças foram impressas em separado e juntadas posteriormente.

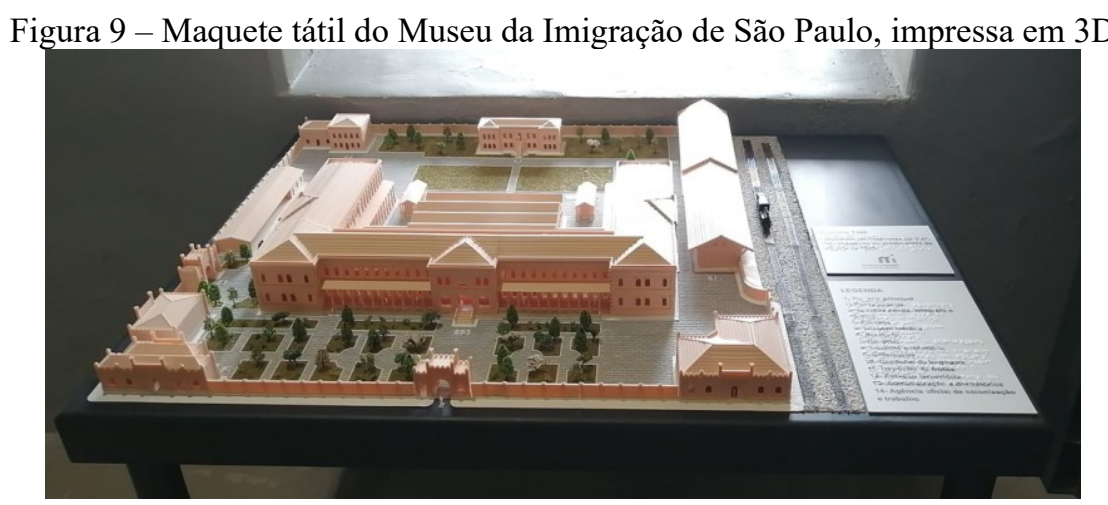

Fonte: Tohmé (2020).

Os exemplos ilustrados nas Figuras 10 e 11, foram desenvolvidos utilizando o software SketchUp a partir de fotografias antigas, com a finalidade de resgate e preservação do patrimônio histórico e cultural da Ruínas de São João Marcos, hoje, Parque Arqueológico e Ambiental de São João Marcos, município de Rio Claro - RJ. O software SketchUp é um software proprietário com versão trial gratuita. A partir de uma antiga planta planialtimétrica, na ocasião, da cidade de São João Marcos, foi gerado o MDT da região e as edificações foram modeladas a partir de fotografias da época. Após a construção do modelo, as distâncias foram verificadas em campo por medidas feitas nas ruínas das edificações ainda existentes. O software SketchUp permite exportar um arquivo em STL. A Figura 10 (a) ilustra uma fotografia antiga de uma das edificações de São João Marcos, a cadeia. A Figura 10 (b) ilustra esta mesma edificação modelada no software SketchUp e a Figura 10 (c) ilustra a mesma edificação impressa. A Figura 11 ilustra o modelo completo, feito em SketchUp, com 8 edificações e o MDT, que também pode ser impresso para fins de contribuição do resgate e preservação do patrimônio histórico e cultural. 
Figura 10 - Edificação modelada e impressa: (a) fotografia da época, (b) modelo em SketchUp e o (c) modelo 3D impresso.

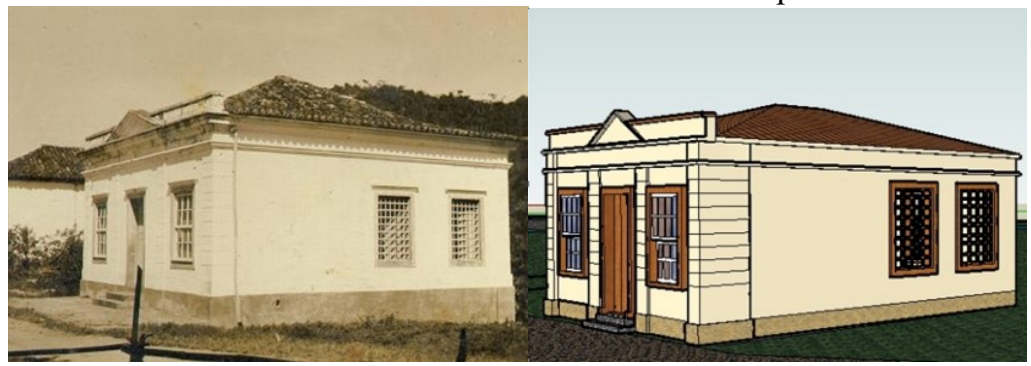

(a)

(b)

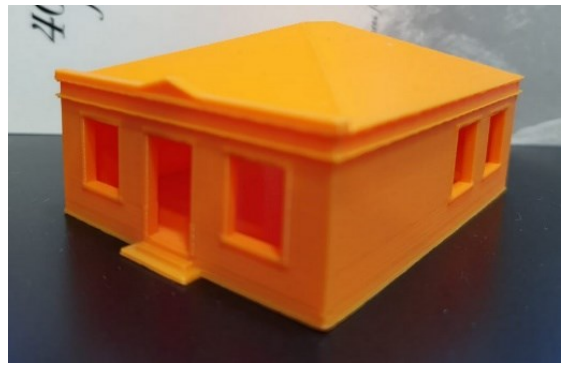

(c)

Fonte: (a) e (b) Siqueira e Fosse (2013), (c) Os autores (2021).

Figura 11 - Modelo completo de São João Marcos.

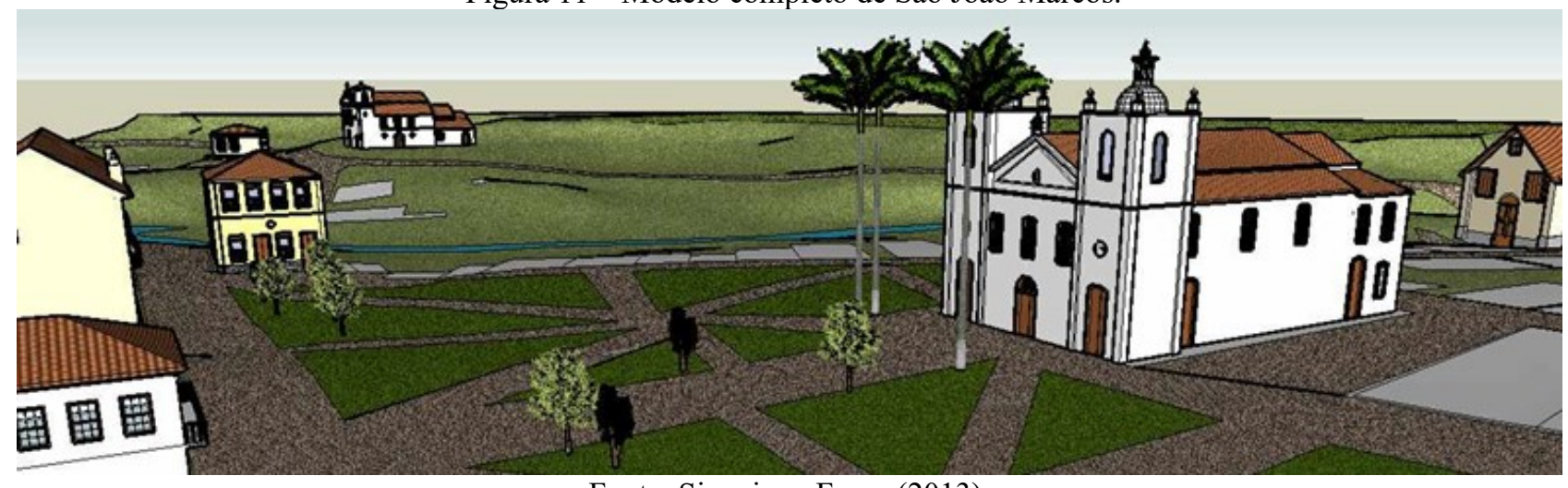

Fonte: Siqueira e Fosse (2013).

Outra possibilidade de geração de modelo 3D para fins cartográficos no sketchUp é com o uso de dados provenientes do mapeamento OpenStreetMap (http://www.openstreetmap.org). O OpenStreetMap é um projeto de mapeamento web colaborativo, que trabalha com informações geográficas voluntárias (VGI), visando construir e manter um extenso banco de dados geográfico contendo mapas editáveis de todos os locais do mundo (ARSANJANI et al., 2015). Existem pelo menos três possibilidades de geração de modelos 3D usando o SketchUp e os dados do OpenStreetMap: o complemento SKP2OSM, o aplicativo on line CADMapper e o complemento PlaceMaker. O SKP2OSM (https://wiki.openstreetmap.org/wiki/Skp2osm) é gratuito e de menor qualidade quanto ao número de edificações disponíveis e em real tamanho. $\mathrm{O}$ aplicativo CADMapper (https://cadmapper.com) permite baixar, de forma gratuita, dados referentes ao MDT, às edificações e ao sistema viário de uma região, desde que a área seja menor que $1 \mathrm{~km}^{2}$, acima deste tamanho é necessário pagar para ter acesso aos dados. Este aplicativo tem qualidade intermediária entre os três. O complemento PlaceMaker (https://www.suplacemaker.com), por sua vez, permite baixar dados de relevo (MDT), edificações, árvores, sistema viário, corpos d'água, imagens aéreas de alta resolução e outras informações. Há uma versão gratuita e outra paga desse complemento. A Figura 12 (a) ilustra um modelo 3D do Centro Politécnico da UFPR gerado no SketchUp com dados do OpenStreetMap pelo complemento PlaceMaker. Na Figura 12 (b) e (c) o modelo está impresso e com uma base de apoio gerada no aplicativo Windows $3 D$ Builder, com uma vista geral e parcial, respectivamente. 
Figura 12 - Modelo 3D do Centro Politécnico da UFPR: (a) como visto no PlaceMaker, (b) impresso em uma visão geral e (c) em uma vista em detalhe das edificações.

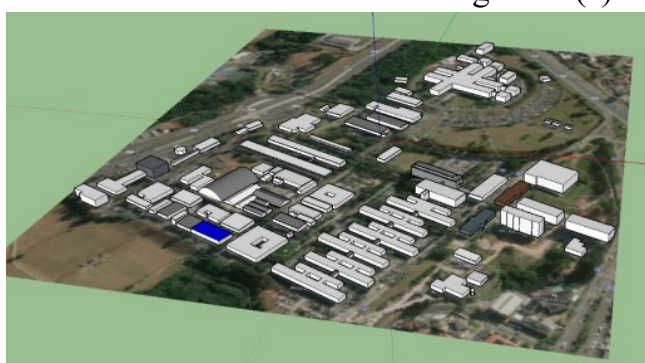

(a)

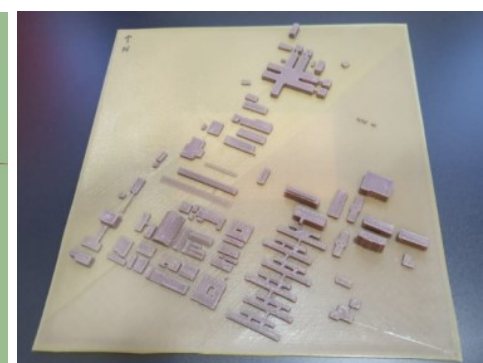

(b)

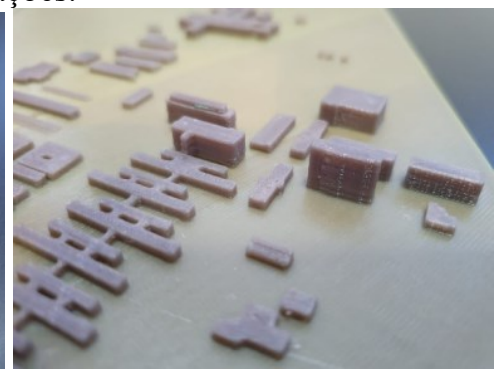

(c)

Fonte: Os autores (2021).

A tecnologia de impressão também tem sido usada como ferramenta para auxiliar a inclusão de pessoas portadoras de deficiência, nesse caso, deficientes visuais. Uma maneira da Cartografia fazer a sua parte neste processo é através dos mapas táteis como mostram os trabalhos de Bem e Pupo (2019), Carrera et al. (2017), Degreas e Katakura (2016), Fernandes et al. (2016), Freire (2018), Gual-Orti et al. (2015), Touya et al. (2019). É de suma importância a existência e acessibilidade do mapa tátil para que as pessoas portadoras de deficiência visual possam obter informações corretas de forma autônoma para seu deslocamento e conhecimento do local. A tecnologia de impressão 3D pode favorecer a geração de mapas táteis de forma menos artesanal, elaborar exemplares mais invariáveis e buscar uma padronização desse tipo de mapa. Dois exemplos são apresentados a seguir: do campus Seropédica da UFRRJ e do campus Centro Politécnico da UFPR. A Figura 13 ilustra o mapa tátil do campus Seropédica impresso em PLA azul, onde foram materializadas as suas principais edificações e as principais vias de acesso.

Figura 13 - Mapa tátil do campus Seropédica da UFRRJ, com as principais edificações e vias de acesso.

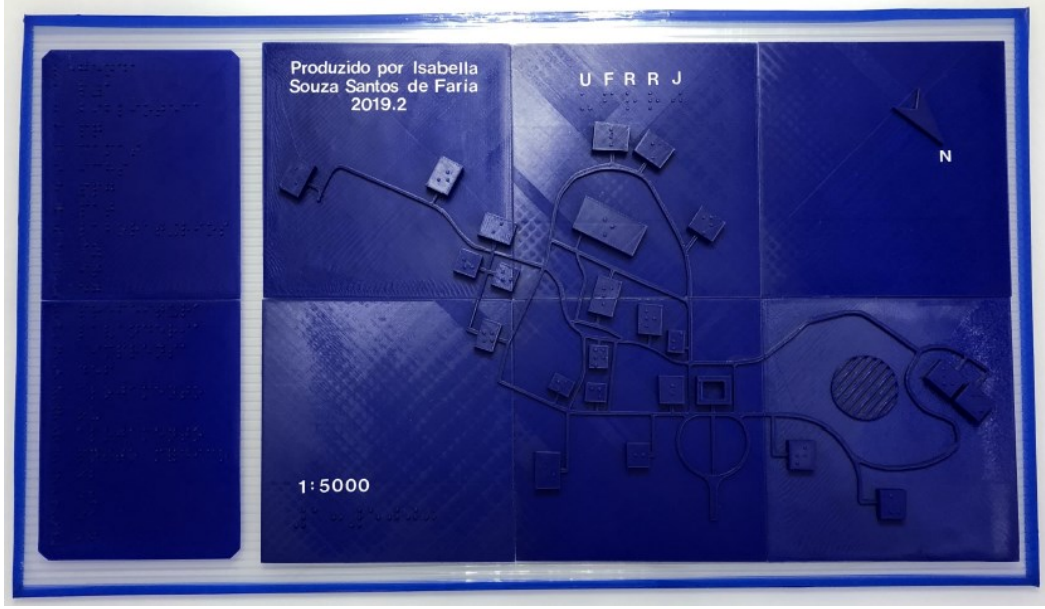

Fonte: Faria (2019).

A Figura 14 (a) ilustra o mapa tátil do Centro Politécnico da UFPR impresso em PLA branco e posicionado em um pedestal, de acordo com as normas ABNT NBR 9050:2015 (Acessibilidade a edificações, mobiliário, espaços e equipamentos urbanos). O mapa tátil da UFPR é equipado com um sistema sonoro capaz de auxiliar o portador de deficiência visual a se localizar no modelo impresso, através de instruções de uso gravadas em áudio com a indicação da localização do mapa impresso, legenda, e instruções impressas em braille. Outro diferencial do trabalho de Freire (2018) é o uso de diferentes tipos de texturas para a simbolização de diferentes feições representadas no mapa tátil. A Figura 14 (b) ilustra a área de estacionamento, gramado e vias públicas representadas por diferentes texturas impressas. Junto com a textura, o espaçamento é outra variável importante que auxilia os leitores do mapa tátil no reconhecimento das feições mapeadas e das respectivas distâncias proporcionais entre essas feições, permitindo um maior reconhecimento do espaço que 
será percorrido por esse usuário. Para que a leitura do mapa tátil possa resultar em uma compreensão clara por parte de seus leitores é necessário que haja um layout bem balanceado com uso das texturas e dos espaçamentos para evitar o que Touya et al. (2019) denominam congestionamento de símbolos. Vale ressaltar que nos dois exemplos citados, mapa do campus da UFRRJ (FARIA, 2019) e do campus da UFPR (FREIRE, 2018), foram realizados testes de percepção com pessoas com deficiência visual para a verificação da Comunicação Cartográfica.

Figura 14 - Mapa tátil do campus Centro Politécnico da UFPR: (a) afixado em um pedestal e equipado com tecnologia assistiva, (b) exemplo de textura aplicada.

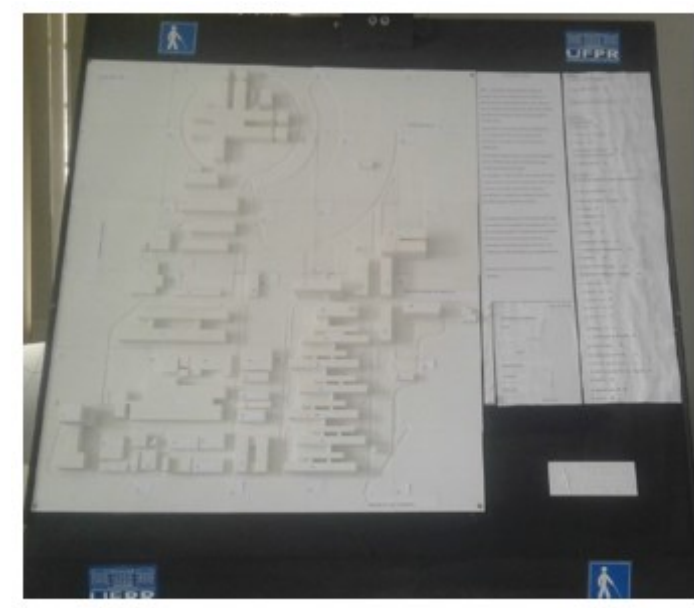

(a)

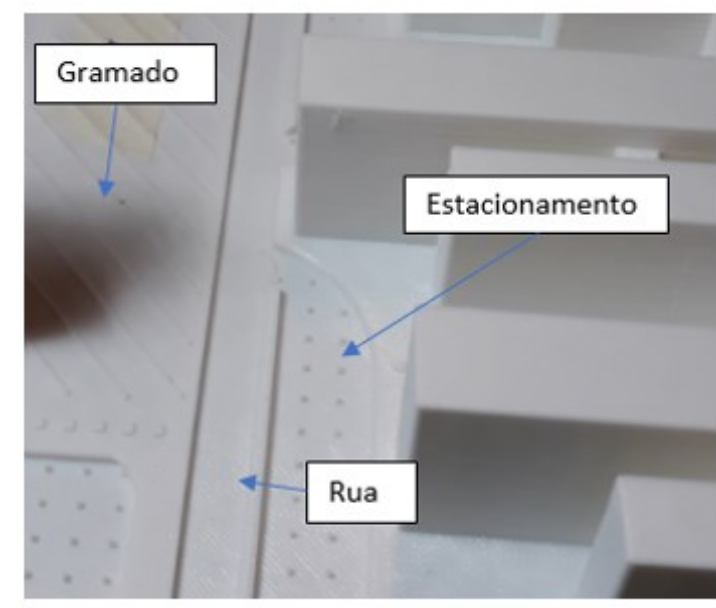

(b)

Fonte: Freire (2018).

\section{CONSIDERAÇÕES FINAIS}

O trabalho apresentou os conceitos relativos à impressão 3D e diferentes usos desta tecnologia na Cartografia. Sem dúvidas, o maior ganho da geração de produtos cartográficos por meio da técnica de AD é a visualização, onde o processo mental feito para a leitura e interpretação da área representada pode ser agilizado e favorecido, principalmente para pessoas de restrito conhecimento geográfico. A tecnologia de impressão 3D não veio substituir outras tecnologias e formas de fazer mapas, mas sim agregar, como mais uma forma de materializar a informação e ajudar na aquisição de conhecimento e tomada de decisão. A Cartografia, como ciência, tem muito a ganhar com essa tecnologia, mas antes é necessário aprender como adaptar a linguagem cartográfica para esta nova forma de representação.

É possível estabelecer um conjunto de vantagens no uso AD nas Ciências Cartográficas, como a visualização, onde há possibilidade de visualizar de um produto 3D sem a necessidade de aparatos tecnológicos permitindo ampliar o grupo de potenciais usuários e possibilitando a criação de produtos para usuários que tenham algum tipo de deficiência visual, que possa "ver" através do tato. Outra vantagem desta tecnologia é o seu grande potencial na geração de material didático para ensino, conforme ilustrados pelos exemplos anteriores, com o adicional de serem produtos duráveis, destacando-se desta forma também a possibilidade de personalização, agilidade de produção, facilidade de disponibilização e, como os arquivos para impressão seguem um padrão, isto facilita muito o compartilhamento. Do ponto de vista de produção destacam-se a reaplicabilidade dos modelos, a possibilidade de detalhamento, conforme a necessidade e a escala do produto, redução de custos de produção e de materiais, sua grande versatilidade, onde a concepção de objetos complexos pode ser dividida em objetos mais simples ou até mesmo a criação de produtos sustentáveis, uma vez que alguns tipos de filamentos, como o PLA e PETG, que são biodegradáveis. Nesse mesmo contexto, também podem ser citadas algumas limitações dessa tecnologia e que necessitam serem melhor estudadas, tais como o tamanho da área útil para impressão 3D e consequentemente a necessidade de dividir a impressão em partes para serem posteriormente unidas, criando assim questões a serem estudadas referentes à união física das peças (colagem) e o acabamento entre elas de forma a não criar descontinuidades na representação cartográfica. 
A cor traz consigo outro elemento para reflexão no que se refere a forma de inserir topônimos no mapa. Se o mapa for gerado por um único filamento, como garantir a legibilidade dos rótulos (labels)? Não se trata de uma solução simples, pois recorrer a técnicas no campo da teoria da percepção gestalt como, figura/fundo, como era feito com os mapas tradicionais monocromáticos pode não surtir o mesmo efeito, já que aqui tratase de uma mesma cor. A inserção de texto impresso com filamentos de cores distintas aos usados para imprimir as demais informações cartográficas do mapa, poderá resolver parcialmente o problema, mas há necessidade de estudos específicos nessa área. Se houver uma definição de camadas dentro do fatiamento, específicas para imprimir os rótulos, quando o usuário trocar o filamento, para um filamento de outra cor, e reiniciar a impressão, não apenas os labels terão alterações nas cores, como todos os objetos nesta mesma altura. Ademais, outra necessidade de estudo nessa área é sobre a pigmentação dos filamentos, se há alguma mudança com efeito do aquecimento ou se poderá haver deterioração ou mudança de cor da peça impressa com o tempo.

Outra limitação imposta pelo uso dessa tecnologia é o uso de filamentos termoplásticos condicionado as especificações técnicas da impressora que, muitas das vezes, está atrelada ao modelo da impressora, tal como ser uma impressora "aberta" ou "fechada" ou possuir ou não mesa "aquecida". Além da limitação imposta pelo modelo da impressora, o mercado brasileiro ainda pode ser considerado restrito e, por vezes, dependente do mercado internacional para abastecimento interno. Logo, em certas circunstâncias, está sujeito à falta de matéria prima específica.

Ainda ocorrem problemas ligados a falta de padronização dos elementos da representação cartográfica. Isso porque, no contexto da construção dos mapas, elementos essenciais para espacialização dos dados devem ser considerados, tais como o título, a orientação, a escala gráfica, a legenda, os topônimos, origem e data de aquisição dos dados, o sistema de coordenadas usado, entre outros. Estes elementos são comumente empregados nos mapas tradicionais, entretanto pouco se sabe sobre a maneira correta de sua aplicação nos produtos cartográficos 3D. A elaboração de layouts de forma coerente e harmônica para com o conteúdo mapeado exige ainda reflexão, experimentos e testes com os grupos de usuários que irão utilizar esses produtos.

As primitivas gráficas ponto, linha e polígono, consolidadas na cartografia convencional, dão lugar as primitivas volumétricas. Se o ponto é uma unidade adimensional e a linha só tem dimensão em um sentido, no ambiente 3D, todas as unidades necessariamente possuem, no mínimo, a dimensão de altura. Se um ponto ou uma linha são demasiadamente finos, dificilmente conseguirão ser representados com eficiência no modelo 3D.

Quanto às variáveis visuais, estas precisam ser mais bem estudadas para que possamos entender melhor o seu comportamento no modelo 3D impresso. A cor (tom, luminosidade e saturação) é definida em quase a totalidade dos casos pelo tom de cor do filamento, que dependerá do fornecedor ou até mesmo do lote utilizado. Trabalhar com diferentes classes de luminosidade e saturação de cor em um mapa impresso 3D tornase mais complicado. A solução seria usar uma impressora que usa tinta e filamento junto, mas pode ser uma alternativa ainda muito cara para os dias atuais. Entretanto, as variáveis visuais tamanho e forma, podem ser exploradas com bastante eficiência e com muitas possibilidades de variação. Tanto o tamanho quanto a forma podem ser variados para criar novas classes, tanto no plano xy quanto na altura z. Entretanto, muitas classes diferentes de tamanho ou forma em um único produto cartográfico podem dificultar o entendimento do usuário. A orientação, a textura e o arranjo são materializados no plano xy e se tornam inviáveis se aplicadas em pequenas áreas, entretanto, em áreas maiores são perfeitamente aplicáveis.

Uma das áreas da Cartografia que mais tem ganhado destaque na impressão 3D é a produção de mapas táteis, que pode ser fabricado em escala, ser menos artesanal e ter símbolos e texturas padronizados. Entretanto, a impressão do texto braile por meio de impressora 3D FDM tem se mostrado pouco eficiente, pois as dimensões desse tipo de escrita é muito pequena e a resolução da impressora 3D FDM é insuficiente. Em alguns experimentos feitos pelos autores o texto braile impresso se rompeu/não fixou na base e em outros se fixou, mas criou uma ponta no topo do ponto proporcionando um tatear áspero para o leitor. Uma alternativa a esses problemas é o uso da impressora 3D SLA, que possui uma resolução melhor, entretanto, outros pontos desfavoráveis irão surgir com a troca de um tipo de impressora por outra, tais como uma menor área útil, preço mais caro do equipamento e da matéria prima.

A popularização das impressoras 3D na Cartografia poderá estimular as pesquisas para a definição de 
soluções em termos de simbologia, uso de cores, e outros elementos cartográficos e assim estas questões em breve poderão encontrar suas respostas.

\section{Agradecimentos}

Agradecemos a todos os pesquisadores e educadores que se mantiveram atuantes nesses tempos tão difíceis decorrentes da pandemia do COVID-19. Agradecemos ao esforço coletivo dos autores, que aqui realizaram uma parceria de trabalho interinstitucional, sem nenhum tipo de fomento, dependendo unicamente de recursos próprios, para gerar os produtos e as discussões apresentados no presente artigo.

\section{Contribuição dos Autores}

O presente trabalho foi redigido de forma equitativa, tendo em vista que se trata de uma produção conjunta de quatro pesquisadores, que partilharam dos mesmos referenciais teórico-conceituais e de produtos gerados em suas respectivas pesquisas acadêmicas. Os métodos e processos apresentados baseiam-se nas formas mais recorrentes de produção por manufatura aditiva, que os autores vêm empregando em seus experimentos práticos. As figuras aqui apresentadas, como etapas construtivas e/ou como produtos foram geradas pelo segundo e terceiro autor em softwares de modelagem tridimensional e hardwares de impressão 3D. Toda a parte de revisão de formatação do template, execução das correções solicitas pelos revisores e correções gramaticais foram efetuadas em conjunto pelos quatro autores.

\section{Conflitos de Interesse}

Os autores declaram que não há conflitos de interesse.

\section{Referências}

ASSOCIAÇÃO BRASILEIRA DE NORMAS TÉCNICAS. NBR 9050: Acessibilidade a edificações, mobiliário, espaços e equipamentos urbanos. Rio de Janeiro, 2015.

AHRENS, C. H. Processos de AM por Fotopolimerização em Cuba. In: VOLPATO, N. (Ed.). Manufatura aditiva: tecnologias e aplicações da impressão 3D. São Paulo: Blucher, 2017. p. 129-144.

ARSANJANI, J. J.; ZIPF, A.; MOONEY, P.; HELBICH, M. An Introduction to OpenStreetMap in Geographic Information Science: Experiences, Research, and Applications. In: ARSANJANI, J. J.; ZIPF, A.; MOONEY, P.; HELBICH, M. OpenStreetMap in GIScience: Experiences, Research, and Applications. Heidelberg: Springer, 2015. p. 1-15.

BEM, G. M.; PUPO, R. T. Parâmetros de Fabricação de Símbolos para Mapas Táteis. Revista Brasileira de Cartografia, v. 71, n. 4, pp. 983-1013. 2019. DOI. 10.14393/rbcv71n4-50377

BERLYANT, A. M. Theoretical Concepts in Cartography, Mapping Sciences and Remote Sensing, v. 31, n. 4, p. 279-287, 1994. DOI 10.1080/07493878.1994.10641973

BANDROVA, T. Innovative Technology for the Creation of 3d Maps. Data Science Journal, v. 4, 2005.

BRUNET, R. La Carte: Mode D'emploi. Paris: Fayard/Reclus, 1987. 270p.

BORILLE. A. V. Prototipagem rápida ou manufatura aditiva? Aplicações na indústria de moldes. Ferramental: Revista Brasileira da Indústria de Ferramentas. Ano VI, n.31, p.11-18. 2010.

CARrerA, C. C.; AVARVAREI, B. V.; CHElARIU, E. L.; DRAGHIA, L.; AVARVAREI, S. C. MapReading Skill Development with 3D Technologies, Journal of Geography, v. 116, n. 5, p. 197-205, 2017. DOI. 10.1080/00221341.2016.1248857

DEGREAS, H. N.; KATAKURA, P. Mapas Táteis: Orientação e Mobilidade em Ambiente Urbano. Revista 
Brasileira de Cartografia, v. 68, n. 8, pp. 1553-1570. 2016.

FARIA, I. S. S. Geração de mapa tátil da UFRRJ em impressora 3d FFF para orientação e navegação de pessoas com deficiência visual. 2019. 44 p. Monografia (Bacharelado em Engenharia de Agrimensura e Cartográfica) - UFRRJ. Seropédica, 2019.

FOGGiATtO, J. A.; SILVA, J. V. L. Representação Geométrica 3D para AM. In: VOLPATO, N. (Ed.). Manufatura aditiva: tecnologias e aplicações da impressão 3D. São Paulo: Blucher, 2017. p. 69-95.

FERNANDES, V. de O.; ALIXANDRINI JUNIOR, M. J.; FOSSE, J. M.; FILHO, D. L.; SILVA, M. da. Produção de Símbolos Táteis Construídos com Impressora 3D para Mapas de Orientação ao Visitante. Revista Brasileira de Cartografia, v. 68, n. 3, p. 481-493, 2016.

FREIRE, K. D. M. A Engenharia Cartográfica e de Agrimensura como ferramenta de inclusão: mapa para orientação e mobilidade de pessoas com deficiência visual no Centro Politécnico da UFPR. 2018. 53 f. Monografia (Curso de Engenharia Cartográfica e de Agrimensura) - Universidade Federal do Paraná, Curitiba, 2018.

GRIESER, F. FDM vs SLA: The Differences - Simply Explained, Oct. 2019. Disponível em: $<$ https://all3dp.com/fdm-vs-sla/> Acesso em: jun. 2020.

GIBSON, I.; ROSEN, D. W.; STUCKER, B. Additive Manufacturing Technologies Rapid Prototyping to Direct Digital Manufacturing. Heidelberg: Springer, 2010.

GUAL-ORTI, J.; PUYUELO-CAZORLA, M.; LLOVERAS-MACIA, J. Improving Tactile Map Usability through 3D Printing Techniques: An Experiment with New Tactile Symbols. The Cartographic Journal, v. 52, n. 1 p. 51-57, 2015. DOI. 10.1179/1743277413Y.0000000046

HASIUK, F. J.; HARDING, C.; RENNER, A. R.; WINER, E. TouchTerrain: A simple web-tool for creating 3D-printable topographic models. Computers \& Geosciences, v. 109, p. 25-31, 2017. DOI. 10.1016/j.cageo.2017.07.005

HOROWITZ, S. S.; SCHULTZ, P. H. Printing Space: Using 3D Printing of Digital Terrain Models in Geosciences Education and Research. Journal of Geoscience Education, v. 62, n.1, p. 138-145, 2014. DOI. 10.5408/13-031.1

INTERNATIONAL ORGANIZATION FOR STANDARDIZATION. ISO/ASTM 52900:2015, Additive manufacturing - General principles - Terminologie. 2015.

MARTINELLI, M.; SALOMÃO GRAÇA, A. J. Cartografia Temática: Uma Breve História repleta de inovações. Revista Brasileira de Cartografia, v. 67, n. 4, p. 913-928, 2015.

PEARSON, A. W. Relief Model. Cartography in the twentieth century, Edited by Mark Monmonier (2015). Disponível em: < https://press.uchicago.edu/books/HOC/HOC_V6/HOC_VOLUME6_R.pdf>. Acesso em: jul. 2020

PECHO, P.; AŽALTOVIČ, V.; KANDERA, B.; BUGAJA, M. Introduction study of design and layout of UAVs 3D printed wings in relation to optimal lightweight and load distribution. Transportation Research Procedia, v. 40, p. 861-868, 2019. DOI. 10.1016/j.trpro.2019.07.121

PETRIE, G.; TOTH, C. K. Terrestrial Laser Scanners. In: SHAN, J.; TOTH, C. K. Topographic Laser Ranging and Scanning: Principles and Processing. Boca Raton: CRC Press, 2018. p. 19-88.

ROBINSON, A. H.; MORRISON, J. L.; MUEHRCKE, P. C.; KIMERLING, A. J. Elements of Cartography. New York: John Willey \& Sons, 6rd ed., 1995.

SALISHCHEV, K. A. Scientific Concepts and Methods in Cartography. Mapping Sciences and Remote Sensing, v. 22, n. 1, p. 1-7, 1985. DOI 10.1080/07493878.1985.10641569

SANTOS, J. R. L. dos. A manufatura aditiva no design de produtos. In: VOLPATO, N. (Ed.). Manufatura aditiva: tecnologias e aplicações da impressão 3D. São Paulo: Blucher, 2017. p. 31-44.

SILVA, A. P. R.; AYABE, E. M. Aplicação da metodologia HBIM na documentação arquitetônica do Museu Paranaense a partir dos levantamentos com laser scanner terrestre (LST) e plataformas VANT. 2019. 77p. Monografia (Curso de Engenharia Cartográfica e de Agrimensura) - Universidade 
Federal do Paraná, Curitiba, dezembro de 2019.

SIQUEIRA, J. C. dos S., FOSSE, J. M. Uso da Cartografia 3D para o resgate e preservação do patrimônio histórico da cidade de São João Marcos - RJ. Simpósio Brasileiro de Sensoriamento Remoto - SBSR, XVI, 13 a 18 de abril de 2013, Foz do Iguaçu, PR, Brasil. Anais... INPE, 2013. p. 2062 - 2068.

ŠTAMPACH, R.; MULÍČKOVÁ, E. Automated generation of tactile maps. Journal of Maps, v. 12, n. sup1, p. 532-540, 2016. DOI. 10.1080/17445647.2016.1196622

THOMPSON, M. K.; MORONI, G.; VANEKER, T.; FADEL, G.; CAMPBELL, R. I.; GIBSON, I.; BERNARD, A.; SCHULZ, J.; GRAF, P.; AHUJA, B.; MARTINA, F. Design for Additive Manufacturing: Trends, opportunities, considerations, and constraints. CIRP Annals - Manufacturing Technology, v. 65, n. 2, p. 737-760, 2016. DOI 10.1016/j.cirp.2016.05.004

TOHMÉ, M. B. (Fotógrafo). Acervo pessoal. 2020.

TOUYA, G.; CHRISTOPHE, S.; FAVREAU, J. M.; RHAIEM, A. B. Automatic derivation of on-demand tactile maps for visually impaired people: first experiments and research agenda, International Journal of Cartography, v. 5, n.1, p. 1-25, 2019. DOI: 10.1080/23729333.2018.1486784

VIRTANEN, J. P.; HYYPPÄ, H.; KURKELA, M.; VAAJA, M.; ALHO, P.; HYYPPÄ, J. Rapid Prototyping - A Tool for Presenting 3-Dimensional Digital Models Produced by Terrestrial Laser Scanning. ISPRS International Journal of Geo-Information, v. 3, n. 3, p. 871-890, 2014. DOI 10.3390/ijgi3030871

VOLPATO, N. Processos de AM por Extrusão de Material. In: VOLPATO, N. (Ed.). Manufatura aditiva: tecnologias e aplicações da impressão 3D. São Paulo: Blucher, 2017. p. 145-179.

VOLPATO, N.; CARVALHO, J. de. Introdução à manufatura aditiva ou impressão 3D. In: VOLPATO, N. (Ed.). Manufatura aditiva: tecnologias e aplicações da impressão 3D. São Paulo: Blucher, 2017. p. 1530.

VOLPATO, N.; SILVA, J. V. L. Planejamento de Processos para Tecnologias de AM. In: VOLPATO, N. (Ed.). Manufatura aditiva: tecnologias e aplicações da impressão 3D. São Paulo: Blucher, 2017. p. 97127.

YURCI, C.; DURAKBASA, N. M. The Importance of CT in Industry 4.0 by Supplying Quality and GPS Standards for Several Production Methods Such as Additive Manufacturing. In: WANG, L.; MAJSTOROVIC, V.; MOURTZIS, D.; CARPANZANO, E.; MORONI, G.; GALANTUCCI, L. (eds.). International Conference on the Industry 4.0 Model for Advanced Manufacturing. Lecture Notes in Mechanical Engineering, $5^{\text {th }}, 2020$, Berlim. Proceedings... Berlim: Springer, 2020, p. 80-91.

\section{Biografia do autor principal}

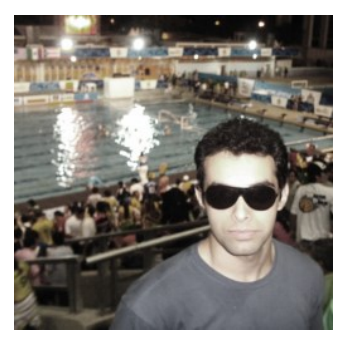

Alan José Salomão Graça é Professor Assistente da Universidade do Estado do Rio de Janeiro (UERJ), Departamento de Engenharia Cartográfica. Atua nas linhas de pesquisas de Sistemas e Sensores, Cartografia Multimídia, Cadastro Territorial e Geoinformática. Atua como Editor Assistente da RBC (Revista Brasileira de Cartografia) vinculada a Sociedade Brasileira de Cartografia, e Editor Assistente da RBGEO (Revista Brasileira de Geomática).

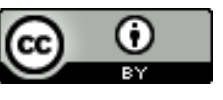

Esta obra está licenciada com uma Licença Creative Commons Atribuição 4.0 Internacional - CC BY. Esta licença permite que outros distribuam, remixem, adaptem e criem a partir do seu trabalho, mesmo para fins comerciais, desde que lhe atribuam o devido crédito pela criação original. 